\title{
Princípios de economia circular para o desenvolvimento de produtos em arranjos produtivos locais
}

\author{
Principles of circular economy for the development of products in industrial \\ clusters
}

\author{
Principios de economía circular para el desarrollo de productos en \\ aglomeraciones productivas locales
}

\author{
Fábio Ribeiro de Oliveira ${ }^{1}$ \\ Sergio Luiz Braga França ${ }^{1}$ \\ Luís Alberto Duncan Rangel ${ }^{1}$
}

Recebido em 06/04/2018; revisado e aprovado em 15/05/2018; aceito em 25/06/2018

DOI: http://dx.doi.org/10.20435/inter.v20i4.1921

\begin{abstract}
Resumo: Diante das ações globais de expansão de estratégias de produção e consumo sustentáveis, este artigo objetiva agregar princípios de economia circular no processo de desenvolvimento de produtos em arranjos produtivos locais. A metodologia contemplou uma revisão sistemática da literatura e análises documentais, possibilitando, a partir da identificação das particularidades dos arranjos, a composição de um modelo de desenvolvimento de produtos orientado ao pensamento do ciclo de vida e à economia circular.

Palavras-chave: arranjos produtivos locais; economia circular; desenvolvimento de produtos; sustentabilidade; ciclo de vida.

Abstract: In the face of global actions to expand sustainable production and consumption strategies, this article aims to add principles of circular economy in the process of product development in industrial clusters. The methodology covered a systematic review of the literature and documentary analyzes, making it possible, from the identification of the particularities of the clusters, the composition of a product development model oriented to life cycle thinking and circular economy

Keywords: industrial cluster; circular economy; product development; sustainability; life cycle.

Resumen: Ante las acciones globales de expansión de estrategias de producción y consumo sostenibles, este artículo objetiva agregar principios de economía circular en el proceso de desarrollo de productos en aglomeraciones productivas locales. La metodología contempló una revisión sistemática de la literatura y análisis documentales, posibilitando, a partir de la identificación de las particularidades de las aglomeraciones, la composición de un modelo de desarrollo de productos orientado al pensamiento del ciclo de vida y la economía circular.
\end{abstract}

Palabras clave: aglomeraciones productivas locales; economía circular; desarrollo de productos; sostenibilidad; ciclo de vida.

\section{INTRODUÇÃO}

Os documentos publicados em dezembro de 2015 referentes ao Plano da União Europeia para a Economia Circular e ao Acordo de Paris, ocorrido na 21a Conferência das Partes (COP 21), registram a necessidade de expandir e solidificar as ações voltadas aos ideais de desenvolvimento sustentável, com atenção às alterações climáticas, ao estímulo à Economia Circular (EC) e ao pensamento do ciclo de vida de produtos e serviços.

Tornam-se cada vez mais necessários modelos de produção voltados aos ideais de sustentabilidade. Neste meio, tomando por base as atividades industriais, é essencial um adequado planejamento de produtos e processos por meio de ações que resultem no prolongamento da

\footnotetext{
${ }^{1}$ Programa de Pós-Graduação em Sistemas de Gestão Sustentáveis. Universidade Federal Fluminense (UFF), Niterói, Rio de Janeiro, Brasil.
} 
vida útil daquilo que será produzido ou mesmo que sejam voltadas ao reprocessamento de subprodutos e reintegração à cadeia de produção, aumentando o ciclo de vida.

Neste foco, um sistema de transição para uma EC busca um processo produtivo sustentável em circuito fechado, de modo a otimizar o uso dos recursos e possibilitar ciclos contínuos de reconversão. Além disso, abrange modelos de negócios circulares entre as partes interessadas, o que requer o fortalecimento de ações internas e externas das empresas, com um foco sistêmico e pautado em parcerias.

Quando empresas se estabelecem em proximidade geográfica, como nos vários tipos de clusters industriais, consequentemente há um somatório de impactos ambientais negativos gerados na região. Contudo tal configuração também permite diversas vantagens que devem ser potencializadas, como questões de logística, estabelecimento de ações conjuntas, maiores investimentos em conhecimento e tecnologia, entre outros. No caso dos Arranjos Produtivos Locais (APLS), aglomerações que contam com empresas relacionadas a uma mesma especialização produtiva, os ganhos tendem a ser maiores. Tal condição se dá pelos vínculos de interação e cooperação entre as organizações, com articulação de forças produtivas e sinergias locais, conforme descrito pelos autores Cassiolato, Lastres e Szapiro (2000).

Tomando por base a abordagem de Malaguti (2005) sobre a necessidade de estratégias compartilhadas em APLs para inovações e melhoria na gestão das questões ambientais relacionadas ao desenvolvimento de produtos, esta pesquisa está centrada na possibilidade de adoção de conceitos de EC nos processos de produção das empresas pertencentes a APLs.

Assim, considerando os processos internos de desenvolvimento de produtos e as redes colaborativas externas nas quais estão imersas tais aglomerações, este trabalho objetiva agregar princípios de economia circular no processo de desenvolvimento de produtos em arranjos produtivos locais.

\section{A ECONOMIA CIRCULAR NO CONTEXTO DOS ARRANJOS PRODUTIVOS LOCAIS}

Buxton (2016), ao abordar os resultados da COP 21, indica que houve pouca evolução nas negociações que demonstrassem ações efetivas perante as reais necessidades quanto às mudanças sistêmicas necessárias diante dos cenários de alterações climáticas. Contudo é perceptível um positivo aumento da conscientização social por meio das cobranças resultantes dos movimentos populares, observadas nos diversos tipos de manifestações e fóruns da sociedade civil em prol de uma economia renovável e solidária (BUXTON, 2016).

Repensar os modelos e seus impactos, entre eles as mudanças climáticas, é um desafio que vai do local ao global, na proteção de pessoas, meios de subsistência e ecossistemas, tendo em conta as necessidades urgentes e imediatas de países em desenvolvimento (UNITED NATIONS FRAMEWORK CONVENTION ON CLIMATE CHANGE [UNFCCC], 2015). As transformações, não só na matriz energética, mas na concepção, produção e utilização de bens e serviços, é essencial para mudanças globais nos modelos de negócios (ABRAMOVAY, 2014).

Neste sentido, a EC representa uma oportunidade para essa importante mudança nas empresas, pois as obriga a repensar além das suas pegadas ecológicas e eficiência energética (LEITÃO, 2015). Propõe uma transição para um sistema em que o valor dos produtos, materiais e recursos se mantenha na economia durante o máximo de tempo possível, com a mínima geração de resíduos, propiciando novas formas de inovação e desenvolvimento local (EUROPEAN COMMISSION, 2015). 
Um dos grandes desafios, principalmente no tocante à gestão econômica e ambiental, está relacionado às Micro, Pequenas e Médias Empresas (MPMEs). Muitas destas empresas, principalmente as micro e pequenas, por falta de conhecimento das ferramentas que auxiliem no processo, apresentam dificuldades de gerenciamento das atividades (NASCIMENTO; VALDEZPIZARRO; MORAES, 2013). Tais organizações constantemente enfrentam dificuldades de gestão ao trabalharem com recursos escassos em um cenário de globalização e rápida mudança tecnológica (HOFFMANN; SCHLOSSER, 2001).

No Brasil, focando em inovação e na sustentabilidade em MPMEs, ações de gestão voltadas ao desenvolvimento de produtos devem ser estimuladas prioritariamente em aglomerações de empresas, como APLs ou grupos de uma mesma cadeia produtiva (ANPEI, 2004 apud KACHBA; HATAKEYAMA, 2013).

Os APLs são construídos por um processo de endogenização no território, de dentro para fora, como consequência de uma lógica territorial que contempla especificidades locais como o passado, a cultura e as relações exercidas entre empresas (MENDONÇA, 2008). De acordo com Cassiolato, Lastres e Szapiro (2000), as principais características destes arranjos são: a dimensão territorial; a diversidade das atividades e dos atores; o conhecimento tácito; as inovações e os aprendizados interativos; e a governança.

Neste ponto, os aspectos da EC seriam de grande relevância para tais empresas, pois permitiriam o processo de desenvolvimento de produtos de uma forma mais colaborativa e eficiente, otimizando o fluxo de bens e serviços. Os APLs, aos estabelecerem ações conjuntas, possibilitam o fortalecimento das atividades industriais, com benefícios mútuos para as empresas nele inseridas (COSTA et al., 2018).

O processo de desenvolvimento de produtos envolve os passos, atividades, tarefas, estágios e decisões de um novo produto ou serviço, ou a melhoria de um já existente, ao longo do ciclo de vida (SALGADO et al., 2010). Representa uma alternativa para que pequenas e médias empresas identifiquem oportunidades e alinhem as relações com os demais agentes envolvidos em trabalhos com visões múltiplas e interdisciplinares (MALAGUTI, 2005, p. 60).

Esta visão deve inclusive, progressivamente, transcender os limites da própria empresa, por meio de ações e projetos em parceria com outras empresas do mesmo segmento ou de outros, substituindo a lógica da concorrência individual pura e simples, pela adoção de estratégias que envolvam cadeias ou arranjos produtivos locais, de acordo com complementaridades percebidas, e ganhos de parte a parte. Um trabalho importante cabe às instituições representativas dos setores produtivos, aos centros de pesquisa e desenvolvimento, universidades e órgãos de fomento ao desenvolvimento industrial na agilização e amadurecimento desse processo. Sua participação pode envolver a introdução de novos métodos, o desenvolvimento e transferência de tecnologia, a aplicação de novos materiais e mesmo a identificação de cenários prospectivos relativos a tendências e novas segmentações de mercado, mudanças no estilo de vida e comportamento das pessoas, etc.

\section{MÉTODO DE PESQUISA}

Esta pesquisa qualitativa buscou, de forma exploratória, uma revisão sistemática da literatura para consolidar aspectos ambientais relacionados ao ciclo de vida e aos princípios de EC no desenvolvimento de produtos em APLs. Um procedimento de pesquisa bibliográfica, conforme apontado por Fonseca (2002), é relevante para o levantamento de referências teóricas já 
analisadas e publicadas por meios escritos e eletrônicos. Desta forma, torna-se possível agregar informações e conhecimentos prévios, resultando na análise das diversas posições acerca de um problema (GIL, 2007).

A sequência metodológica está sintetizada na Figura 1 e descrita posteriormente.

Figura 1 - Fases da revisão da literatura, tratamento dos dados e consolidação do modelo

\begin{tabular}{|c|c|c|c|}
\hline Revisão da literatura & Decorrências da revisão & Tratamento dos dados & Resultados \\
\hline $\begin{array}{l}\text { 1- Pesquisa de documentos } \\
\text { e acordos multipaíses } \\
\text { ligados à economia circular. } \\
\text { 2- Revisão sistemática da } \\
\text { literatura, de artigos até o } \\
\text { ano de } 2017 \text {. Bases de } \\
\text { dados Scopus e Web of } \\
\text { Science. Utilização de } \\
\text { termos de busca } \\
\text { relacionados a: economia } \\
\text { circular; desenvolvimento } \\
\text { de produtos; arranjos } \\
\text { produtivos locais. }\end{array}$ & $\begin{array}{l}\text { 1 - Documentos levantados: } \\
\text { Plano de ação da União } \\
\text { Europeia para a economia } \\
\text { circular (02/12/2015); } \\
\text { - } \text { Convenção marco sobre } \\
\text { mudanças climáticas } \\
(12 / 12 / 2015) \text {. } \\
\text { 2- } 32 \text { artigos encontrados na } \\
\text { pesquisa. Realização de filtro } \\
\text { das publicações, resultando } \\
\text { em } 9 \text { artigos selecionados } \\
\text { para análise. } \\
\text { 3- Análise das principais } \\
\text { características de } 35 \text { modelos, } \\
\text { amparada pelo estudo de } \\
\text { Salgado et al. (2010). } \\
\text { Análise da ABNT ISO/TR } \\
\text { 14062 (2004). }\end{array}$ & $\begin{array}{l}\text { 1- Análise das ações e metas } \\
\text { propostas, relacionadas a } \\
\text { modelos de transformação } \\
\text { ligados à economia circular. } \\
\\
\text { 2- Identificação das partes } \\
\text { interessadas e dos aspectos } \\
\text { externos e internos } \\
\text { relacionados à dinâmica dos } \\
\text { APLs. Levantamento dos } \\
\text { requisitos ambientais } \\
\text { relacionados ao } \\
\text { desenvolvimento de } \\
\text { produtos. } \\
\text { 3- Consideração do modelo } \\
\text { de Rozenfeld et al. (2006) por } \\
\text { mostrar uma maior } \\
\text { abordagem à integração de } \\
\text { ferramentas e métodos, além } \\
\text { do pensamento do ciclo de } \\
\text { vida estimulado pela ABNT } \\
\text { ISO/TR 14062 (2004). }\end{array}$ & $\begin{array}{l}\text { Composição do modelo de } \\
\text { desenvolvimento de } \\
\text { produtos voltado ao } \\
\text { pensamento do ciclo de vida } \\
\text { e economia circular em APLs. }\end{array}$ \\
\hline
\end{tabular}

Fonte: Elaboração própria, com base em ABNT (2004); Rozenfeld et al. (2006); Salgado et al. (2010); European Comission (2015); UNFCCC (2015).

Na fase de revisão da literatura, como documentos indutores desta pesquisa, foram considerados os resultados da 21a Convenção Marco sobre Mudanças Climáticas e o Plano de Ação da União Europeia para a Economia Circular, ambos publicados em dezembro de 2015. Foram analisados aspectos voltados ao desenvolvimento local e à EC como propulsores das ações sustentáveis em APLs, trazendo tais conceitos para as etapas de desenvolvimento de produtos.

Utilizaram-se as bases de dados do Scopus e do Web of Science como plataformas para a pesquisa de publicações, visando contemplar artigos de repercussão internacional, com maior relevância para a temática. A pesquisa foi realizada por meio de uma combinação de três diferentes campos de busca relacionados aos conceitos centrais do tema. Consideraram-se as seguintes palavras-chave pertinentes ao objetivo deste trabalho:

- Campo 1: "Circular economy"; "Industrial ecology"; "Sustaina*" (referente às derivações de sustentabilidade); "Cleaner production"; "Life cycle assessment"; "Environmental management"; "Ecoefficiency";

- Campo 2: "Product development"; "Product design", "Product creation";

- Campo 3: Cluster.

Conforme apontado por Cunha e Terra (2008), apesar de haver trabalhos que consideram os termos APL e cluster como sinônimos, os elementos estruturais (principalmente culturais) 
da própria formação histórica da comunidade aglomerada devem ser considerados para se entender a natureza e diferenciação destas redes. Como há uma restrição nas bases de dados internacionais quanto à tradução literal de arranjos produtivos locais, optou-se pela utilização do termo cluster, seguido de uma análise na qual a referência fosse condizente com aspectos de APLs, conforme definições apresentadas na seção 1.1 .

A busca nas bases de dados foi retroalimentada à medida que apareciam novas palavras-chave nos resultados encontrados. Foram considerados todos os artigos contidos nas bases até dezembro de 2017, e, após a eliminação das duplicatas, o quantitativo foi de 32 publicações. Posteriormente, os artigos disponíveis passaram por uma seleção na qual verificou-se o enquadramento do tema e dos termos utilizados, finalizando em um total de nove publicações para comporem a pesquisa. O tratamento e a análise de dados dos artigos resultantes seguiram as seguintes etapas:

1. identificação das partes interessadas e dos aspectos externos e internos relacionados à dinâmica de APLs;

2. levantamento dos requisitos ambientais e princípios de EC a serem associados a cada fase do modelo de desenvolvimento de produtos, com foco no ciclo de vida.

Para selecionar a forma de representação das etapas do desenvolvimento de produtos a ser utilizada de base nesta pesquisa, foi realizada uma prospecção de modelos de desenvolvimento de produtos, tomando como referência o estudo orientado por Salgado et al. (2010), no qual consta uma revisão e análise de 35 modelos, classificando as principais características de cada um. Salgado et al. (2010) ressaltam que a classificação dos modelos permite que pesquisadores possam identificar lacunas na literatura, favorecendo a elaboração de referências para setores industriais ainda não estudados, como APLs, contribuindo para o ensino e o aprendizado.

Entre os modelos elencados optou-se pelo proposto por Rozenfeld et al. (2006) devido a uma abordagem voltada à integração de ferramentas e métodos. Além disso, tal exemplar propicia o pensamento no ciclo de vida do produto permeando todas as etapas do processo, sendo importante para a inclusão de requisitos ambientais e aspectos da EC.

Visando agregar as informações depreendidas nos artigos, os fatores de pensamento no ciclo de vida e os princípios de EC foram elencados nas etapas do desenvolvimento de produtos com base na norma ABNT ISO/TR 14062/2004 (ASSOCIAÇÃO BRASILEIRA DE NORMAS TÉCNICAS [ABNT], 2004): "Gestão ambiental - integração de aspectos ambientais no projeto e desenvolvimento de produto", de caráter informativo.

\section{RESULTADOS E DISCUSSÕES}

\subsection{Os APLs como indutores da economia circular}

A Convenção Marco sobre Mudanças Climáticas evidencia a necessidade de reforçar conhecimentos, tecnologias, práticas e esforços das comunidades locais diante das mudanças climáticas, com o intercâmbio de experiências holísticas e integradas (UNFCCC, 2015). Consequentemente, estimula uma aproximação das organizações para ações conjuntas e o compartilhamento de boas práticas, alinhando-se, assim, aos ideais da EC.

Neste sentido, os eixos norteadores do Plano de Ação da União Europeia para a Economia Circular apresentam algumas práticas e esforços que seriam oportunos a uma visão sistêmica nos processos e no desenvolvimento de produtos nos APLs, focado no pensamento do ciclo de 
vida. Como exemplos de tais práticas, podem ser citados (EUROPEAN COMMISSION, 2015):

- Estímulo à simbiose industrial, permitindo que os resíduos ou subprodutos de uma indústria se tornem insumos para outra;

- Estímulo à utilização eficiente dos recursos nos setores industriais, além das práticas para a gestão dos resíduos e valorização da reciclagem;

- Concessão ecológica, promovendo a reparabilidade, durabilidade e reciclabilidade dos produtos, para além da eficiência energética;

- Responsabilidade alargada do produtor na contribuição com os custos de coleta e tratamento dos resíduos. Neste caso, busca-se também um incentivo econômico aos produtos planejados, de forma que facilitem a reciclagem ou reutilização;

- Normas de qualidade aplicáveis a matérias-primas secundárias, buscando classificar aqueles materiais reinjetados na economia de forma a serem comercializados e transferidos exatamente como as matérias-primas tradicionais;

- Estímulo à reutilização da água;

- edução da presença e aumento da rastreabilidade de químicos nos produtos que possam oferecer riscos à saúde humana e ao meio ambiente.

Quando associada à EC, a aproximação geográfica de empresas pode contribuir para a diminuição dos poluentes atmosféricos lançados no fluxo de bens e insumos. O reaproveitamento e a reciclagem refletiriam em uma menor retirada de insumos do meio e na diminuição de resíduos, efluentes e emissões geradas.

Os esforços de valorização relacionados às atividades de um APL contribuem para o impulsionamento da economia local (CABRERA; SCHULTZ; TALAMINI, 2017) e possibilitam oportunidades para o desenvolvimento regional (MARINI; SILVA, 2012; ANTERO et al., 2016). O associativismo privilegia a cooperação e as ações conjuntas sem desconsiderar as coações impostas pela busca de competitividade sistêmica ou territorial (SINGER, 2002).

Atentando-se para as características descritas, os nove artigos resultantes da revisão sistemática da literatura trazem contribuições relativas a aspectos da EC no desenvolvimento de produtos em APLs, conforme pode ser observado no Quadro 1. O foco de estudo das publicações contemplou diversos setores, a exemplo da produção de móveis, artesanato, químicos e oferta de serviços relacionados ao turismo.

Em seus respectivos trabalhos, Azevedo e Nolasco (2009), Oliveira et al. (2016) e Oliveira, França e Rangel (2018) analisam os requisitos ambientais no ciclo de vida e no processo de desenvolvimento de produtos, desde o planejamento estratégico à descontinuidade do produto. Ruiz-Silveira, Reys e Martínez (2010) e Das (2015) reforçam a importância dos recursos da tradição local, incorporando a lógica de rede e desenvolvimento colaborativo, relacionados ao meio rural.

Somadas a tais contribuições, as pesquisas de Hu, Ling e Chan (2005) e Alfos e Pagès-XatartParès (2012) ressaltam os processos de inovação e os ideais de interação entre os agentes internos e externos aos clusters. Benur e Bramwell (2015) e Dinis e Krakover (2015), ao citarem os clusters de turismo, apresentam uma diversidade de aspectos de sustentabilidade relacionados ao desenvolvimento de produtos e serviços, a exemplo das inter-relações, a identidade cultural e a tradição local. 
Quadro 1 - Resultados da revisão sistemática da literatura

\begin{tabular}{|c|c|}
\hline Autores/Ano/Periódico & Foco de estudo \\
\hline $\begin{array}{l}\text { Hu, Lin e Chang (2005): } \\
\text { Technovation }\end{array}$ & $\begin{array}{l}\text { Analisar a interação e a colaboração entre as empresas de um } \\
\text { arranjo de inovação em Taiwan/ China. }\end{array}$ \\
\hline $\begin{array}{l}\text { Azevedo e Nolasco (2009): } \\
\text { Ciência Rural }\end{array}$ & $\begin{array}{l}\text { Analisar os requisitos ambientais no ciclo de vida e no } \\
\text { processo de desenvolvimento de produtos no APL de móveis } \\
\text { em Itatiba/Brasil. }\end{array}$ \\
\hline $\begin{array}{l}\text { Ruiz-Silveira, Reyes e Martinez (2010): } \\
\text { Espacios }\end{array}$ & $\begin{array}{l}\text { Reforçar a importância dos recursos da tradição local, } \\
\text { incorporando a lógica de rede. Estudo voltado à produção } \\
\text { e inovação no APL de artesanato (bambu) em San Felipe/ } \\
\text { Venezuela. }\end{array}$ \\
\hline $\begin{array}{l}\text { Alfos e Pagès-Xatart-Parès (2012): } \\
\text { OCL - Oleagineux Corps Gras Lipides }\end{array}$ & $\begin{array}{l}\text { Desenvolver um sistema de interação baseado na química } \\
\text { verde em um arranjo químico industrial de Passac/França. }\end{array}$ \\
\hline $\begin{array}{l}\text { Benur e Bramwell (2015): } \\
\text { Tourism Management }\end{array}$ & $\begin{array}{l}\text { Analisar os elementos, conexões, processos de concentração, } \\
\text { intensificação e diversificação de produtos turísticos em } \\
\text { arranjos locais do setor. }\end{array}$ \\
\hline $\begin{array}{l}\text { Das (2015): } \\
\text { Journal of Rural Development }\end{array}$ & $\begin{array}{l}\text { Avaliar impactos do desenvolvimento colaborativo de um } \\
\text { arranjo de artesãos na área rural em Assam/Índia. }\end{array}$ \\
\hline $\begin{array}{l}\text { Dinis e Krakover (2015): } \\
\text { Tourism Planning \& Development }\end{array}$ & $\begin{array}{l}\text { Explorar a contribuição de produtos locais para o } \\
\text { desenvolvimento do turismo sustentável em um parque } \\
\text { museológico. }\end{array}$ \\
\hline $\begin{array}{l}\text { Oliveira et al. (2016): } \\
\text { Espacios }\end{array}$ & $\begin{array}{l}\text { Analisar os requisitos ambientais incorporados à gestão do } \\
\text { desenvolvimento de produtos em arranjos produtivos e } \\
\text { parques industriais. }\end{array}$ \\
\hline $\begin{array}{l}\text { Oliveira, França e Rangel (2018): } \\
\text { Resources, Conservation and Recycling }\end{array}$ & $\begin{array}{l}\text { Contribuir para a expansão da economia circular no Brasil, } \\
\text { identificando os desafios e as oportunidades para um arranjo } \\
\text { produtivo local de móveis. }\end{array}$ \\
\hline
\end{tabular}

Fonte: Elaboração própria, com base em Hu, Lin e Chang (2005), Azevedo e Nolasco (2009), Ruiz-Silveira, Reys e Martínez (2010), Alfos e Pagès-Xatart-Parès (2012), Benur e Bramwell (2015), Das (2015), Dinis e Krakover (2015), Oliveira et al. (2016) e Oliveira, França e Rangel (2018).

A Figura 2 apresenta os principais aspectos e agentes envolvidos no desenvolvimento de produtos em APLs, conforme os artigos analisados e as questões discutidas por meio da COP 21 (UNFCCC, 2015). A parte central da representação é composta por setas indicando as redes de colaboração entre as organizações pertencentes ao arranjo, remetendo a aspectos como EC, inovação, requisitos e tecnologias ambientais. Como exemplos de inovações tecnológicas e demais metodologias, enquadram-se a simbiose industrial, o ecodesign, a produção mais limpa, a avaliação do ciclo de vida e a química verde (OLIVEIRA et al., 2016).

Envolto às diversas partes interessadas, o APL exerce e recebe grande influência do ambiente externo, estando ligado a aspectos como: desenvolvimento local, cultura e tradição, vocação turística, políticas públicas, requisitos legais e normativos, condições econômicas e mercado. 
Figura 2 - Aspectos e agentes envolvidos no desenvolvimento de produtos em APLs

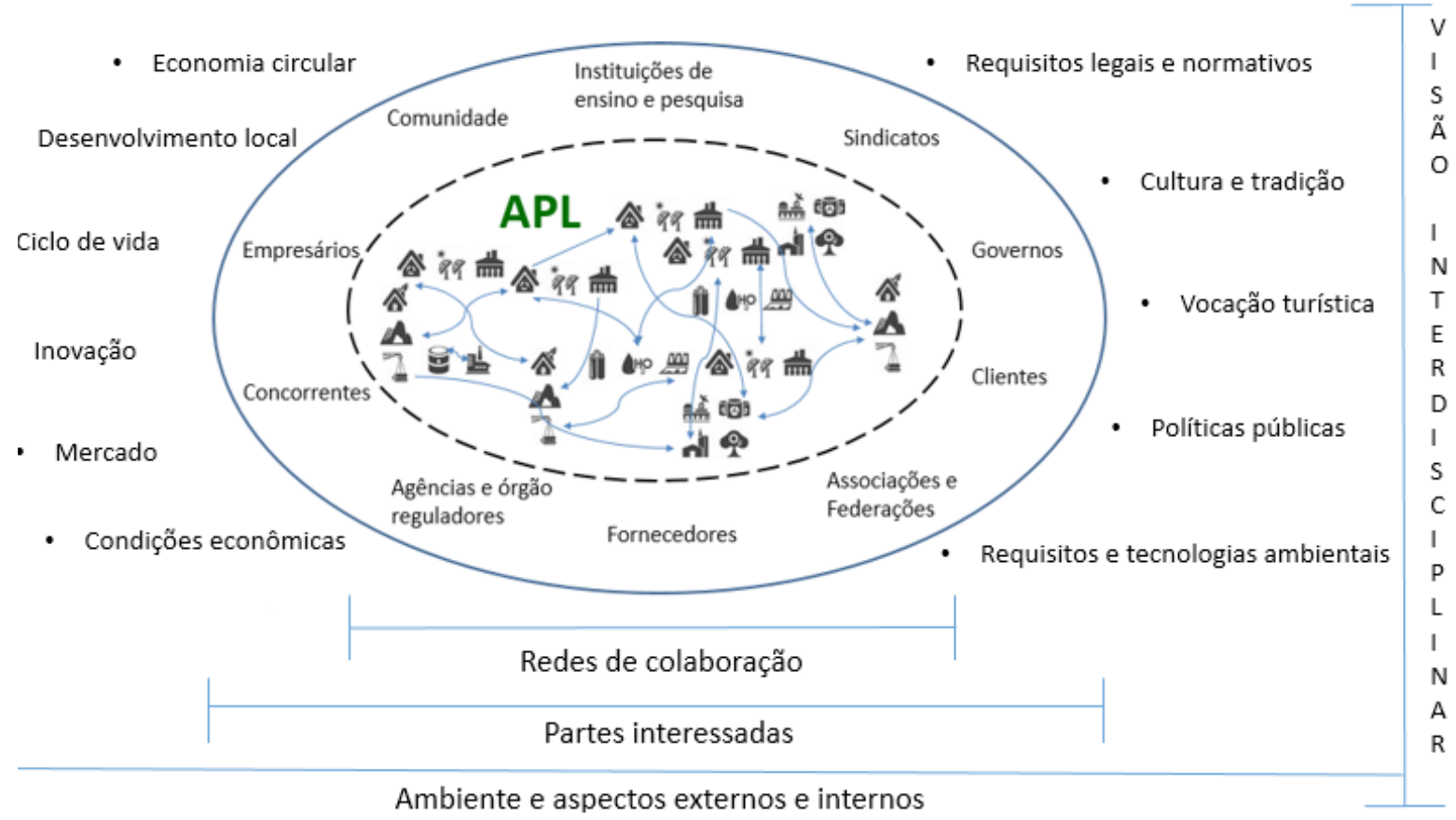

Fonte: Elaboração própria, com base em Hu, Lin e Chang (2005), Azevedo e Nolasco (2009), Ruiz-Silveira, Reys e Martínez (2010), Alfos e Pagès-Xatart-Parès (2012), Benur e Bramwell (2015), Das (2015), Dinis e Krakover (2015), UNFCCC (2015), Oliveira et al. (2016) e Oliveira, França e Rangel (2018).

O desenvolvimento de um APL está intrinsecamente ligado a tais redes de colaboração interna e externa. As redes contribuem para o aperfeiçoamento da densidade técnica, funcional e informacional do espaço, o que fortalece a criação de objetos, condições, infraestruturas, normas, ações e ordens para atender às premissas da fluidez (SILVA, 2014). Neste ponto, além das interações das empresas quanto às práticas de gestão e desenvolvimento de produtos, é fundamental um alinhamento com as partes interessadas quanto a estratégias e parcerias. Os agentes envolvidos precisam se relacionar, estar bem integrados e compartilhar valores e interesses comuns (CABRERA; SCHULTZ; TALAMINI, 2017).

Todos os artigos considerados na análise contemplam, de alguma forma, a lógica de rede com base nas conexões entre a gestão interna às organizações e os interesses dos agentes externos conectados aos APLs. Ressalta-se a visão interdisciplinar das publicações, visto que o contexto estudado demanda uma análise sistêmica, holística e integradora (UNFCCC, 2015) e que abranja os eixos social, econômico, ecológico (ambiental), espacial e cultural da sustentabilidade (SACHS, 2007) .

\subsection{Modelo de desenvolvimento de produtos}

Os princípios de EC, contemplando também requisitos ambientais e o pensamento no ciclo de vida, foram agregados nas etapas prévias (pré), decorrentes e posteriores (pós) ao processo de desenvolvimento de produtos, conforme o modelo de Rozenfeld et al. (2006) (Figura 3).

O modelo, assim como as descrições de cada fase, foi composto com base nas estratégias de EC preconizadas pelo Plano de Ação da União Europeia para a Economia Circular (2015), 
na norma ABNT ISO/TR 14062/2004 (ABNT, 2004), e nos aspectos ambientais depreendidos dos artigos resultantes da revisão sistemática da literatura, principalmente as contribuições de Azevedo e Nolasco (2009), Oliveira et al. (2016), Oliveira, França e Rangel (2018), que descrevem com maior detalhamento as etapas de desenvolvimento de produtos.

\subsubsection{Fase de pré desenvolvimento}

O pré-desenvolvimento, contemplando o planejamento estratégico, passa pelo processo gerencial que envolve os setores funcionais e as diretrizes gerais da empresa. Está relacionado aos aspectos organizacionais internos como inovação; recursos financeiros; especialidades dos envolvidos; capacidade produtiva; área de influência e disponibilidade de tecnologias, componentes e insumos. Faz-se necessário planejar um processo sustentável, com materiais alternativos, e renovação (redesign), considerando a vida útil do produto.

Os aspectos externos incluem necessidades e expectativas do cliente; mercado; análise dos concorrentes; requisitos legais e normativos e expressões sociais como cultura, tradição local e turismo. Há de se considerar a possibilidade de minimização do uso de recursos via parcerias entre organizações envolvidas com o APL, em prol do aproveitamento dos subprodutos de terceiros, buscando o ciclo fechado de produção no arranjo. 


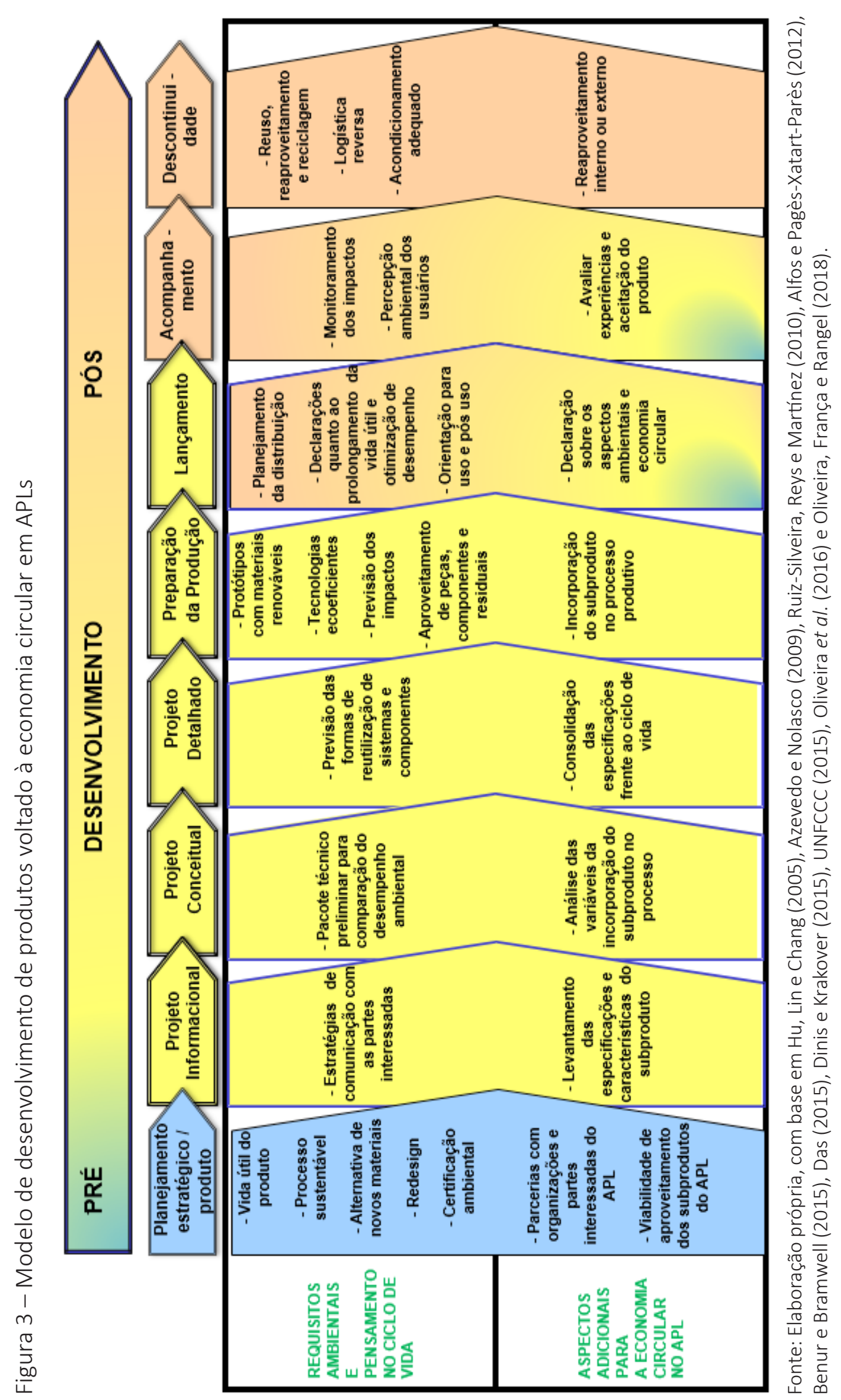




\subsubsection{Fase de desenvolvimento}

A fase de desenvolvimento do produto inclui os projetos informacional, conceitual e detalhado, além da preparação para a produção e o lançamento do produto. Também contempla aspectos internos e externos relevantes à gestão.

No projeto informacional, busca-se elucidar as características que atendam às necessidades da clientela e da organização, de modo que se faz necessário um bom canal de comunicação externo com as partes interessadas, até mesmo para o levantamento de especificações dos subprodutos na expectativa de implementação de princípios de simbiose industrial para a EC.

Em seguida, o projeto conceitual, ao promover a concepção do produto, estabelece o pacote técnico preliminar para a comparação do desempenho ambiental, de forma a considerar a base de dados dos materiais; ferramentas analíticas como a avaliação do ciclo de vida (considerando fontes internas e externas); e a análise de especificações, inclusive das variáveis da incorporação do subproduto no processo.

No projeto detalhado, as informações técnicas são consolidadas, resultando na aprovação do projeto. Como requisitos ambientais, atenta-se para a previsão das formas de reutilização de sistemas e componentes para os produtos, bem como a aprovação das especificações dos subprodutos a serem incorporados no processo.

A transição para a etapa de preparação para a produção conta com um protótipo do produto, priorizando materiais renováveis e resultando na previsão dos impactos ambientais e na avaliação das características do produto com matérias-primas secundárias incorporadas ao processo. Após a aprovação, a produção em escala comercial deve considerar o aproveitamento de peças e componentes.

A etapa de lançamento do produto, voltado principalmente ao ambiente externo da organização, inclui um planejamento das formas de distribuição e declarações sobre a otimização de desempenho, vida útil e demais fatores relacionados à EC, inclusive aos aspectos sociais e ambientais considerados. Além disso, conforme o pensamento no ciclo de vida, são importantes as orientações para uso e pós-uso do produto.

\subsubsection{Fase de pós-desenvolvimento}

O pós-desenvolvimento conta com aspectos externos de acompanhamento e avaliação do produto no mercado e ações voltadas à descontinuidade deste.

A etapa de acompanhamento, visando gerar oportunidades de melhoria, requer um monitoramento dos impactos ambientais e da percepção dos usuários quanto a quesitos como funcionalidade, custo-benefício, reparabilidade e durabilidade, refletindo diretamente na aceitação do produto.

A descontinuidade deve ser planejada considerando-se fatores internos, como novos projetos e inovações, e fatores externos, como concorrência e requisitos legais, a exemplo da responsabilidade alargada do produtor. Devem ser consideradas ações de logística reversa, reúso, reaproveitamento, reciclagem e acondicionamento adequado, nos ideais da EC.

\section{CONSIDERAÇÕES FINAIS}

Os aspectos extraídos da revisão da literatura relacionados às redes de colaboração, às 
partes interessadas e aos fatores externos e internos influentes na dinâmica dos APLs permitiram constatar as características interdisciplinares e sistêmicas que compõe tais àrranjos.

Como tais aglomerações são formadas por um processo territorial endógeno, guiado por relações colaborativas, incentivam-se trabalhos voltados à EC neste contexto, em uma gradual transformação sustentada a partir do desenvolvimento de produtos voltado ao ciclo de vida, conforme os aspectos identificados e o modelo apresentado neste trabalho.

Os aspectos externos e internos influentes na dinâmica do arranjo estão ligados ao nível de evolução do APL, considerando tanto as formas de gestão das organizações componentes como o relacionamento com as partes interessadas. Neste contexto, quanto mais integração entre os agentes houver, maior a aproximação com as pretensões de desenvolvimento local sustentável.

Assim, a EC contribui, de forma ampla, com uma das principais características dos APLs, que é o caráter de colaboração entre as diversas organizações envolvidas. O modelo de desenvolvimento de produtos proposto neste artigo propiciou a identificação dos requisitos ambientais necessários em cada etapa do processo. Além disso, ressaltou a valorização do produto e do subproduto ao longo da cadeia, guiados pela integração dos agentes e pensamento do ciclo de vida.

Salienta-se que tal valorização vai além dos critérios econômicos, muitas vezes trazendo questões mais amplas, como turismo, tradição e identificação cultural. Deste modo, os aspectos e o modelo genérico apresentados neste trabalho devem ser orientados às especificidades e características locais, estando abertos a possíveis adequações necessárias ao objeto de estudo.

As oportunidades sociais, econômicas e ambientais, diretas e indiretas, seriam vantajosas para as organizações e partes interessadas dos APLs brasileiros, contribuindo com as frentes de desenvolvimento local nas várias dimensões da sustentabilidade, conforme metas previstas na COP 21 e demais planos de ação internacionais.

\section{REFERÊNCIAS}

ABRAMOVAY, R. Inovações para que se democratize o acesso à energia, sem ampliar as emissões. Ambiente \& Sociedade. São Paulo, v. 17, n. 3, p. 01-18, jul./set. 2014.

ALFOS, C.; PAGÈS-XATART-PARÈS, X. De l'idée au marché: L'ITERG renforce ses activités dans la chimie verte avec la plateforme CEDOP, Centre européen de développement des oléo-produits. OCL-Oleagineux Corps Gras Lipides, v. 19, n. 1, p. 54-8, 2012.

ANTERO, C. A. S.; TAVARES, B.; ANTONIALLI, L. M.; GAVA, R. Modelo analítico para a compreensão da governança em arranjos produtivos locais (APLs). Revista Brasileira de Gestão e Desenvolvimento Regional, Taubaté, SP, v. 12, n. 3, p. 371-96, set./dez. 2016.

ASSOCIAÇÃO BRASILEIRA DE NORMAS TÉCNICAS (ABNT). ABNT ISO/TR 14062/2004. Gestão ambiental: Integração de aspectos ambientais no projeto e desenvolvimento do produto. Rio de Janeiro: ABNT, 2004.

ASSOCIAÇÃO NACIONAL DE PESQUISA, DESENVOLVIMENTO E ENGENHARIA DAS EMPRESAS INOVADORAS (ANPEI). Como alavancar a inovação tecnológica nas empresas. São Paulo: ANPEI, 2004.

AZEVEDO, P. S.; NOLASCO, A. M. Fatores de incorporação de requisitos ambientais no processo de desenvolvimento de produtos em indústrias de móveis sob encomenda. Ciência Rural, Santa Maria, RS, v. 39, n. 8, p. 2422-7, nov. 2009.

BENUR, A. M.; BRAMWELL, B. Tourism product development and product diversification in destinations. Tourism Management, v. 50, p. 213-24, 2015. 
BUXTON, N. COP 21 charades: spin, lies and real hope in Paris. Globalizations, v. 13, n. 1, p. 934-7, 2016.

CABRERA, L. C.; SCHULTZ, G.; TALAMINI, E. Limites e oportunidades para a construção de um Arranjo Produtivo Local (APL): a experiência do projeto Balde Cheio em Mato Grosso do Sul. Interações, Campo Grande, MS, v. 18, n. 4, p. 19-30, out./dez. 2017.

CASSIOLATO, J.; LASTRES H.; SZAPIRO, M. Arranjos e sistemas produtivos locais e proposições de políticas de desenvolvimento industrial e tecnológico. NT 27- Projeto de pesquisa arranjos e sistemas produtivos locais e as novas políticas. Rio de Janeiro, 2000. Disponível em: http://www.ie.ufrj.br/redesist/P2/textos/ NT27.PDF. Acesso em: 25 out. 2019.

COSTA, E. S.; BITANTE, A. P.; BRITTO, L. C.; PINHEIRO, L. R. D.; FARINA, M. C. Análise das relações e ações conjuntas entre as empresas do APL têxtil da região metropolitana de São Paulo: contribuições para o seu crescimento. Interações, Campo Grande, MS, v. 19, n. 2, p. 401-15, abr./jun. 2018.

CUNHA, J. A. C.; TERRA, L. A. A. Diferenciando os clusters dos arranjos produtivos locais. Ciências Sociais Aplicadas em Revista, Marechal Cândido Rondon, PR, v. 8, n. 15, p. 09-25, 2o sem. 2008.

DAS, R. Cluster development initiative for poverty alleviation: a case study. Journal of Rural Development. v. 34, n. 3, p. 391-403, jul./set. 2015.

DINIS, A.; KRAKOVER, S. Niche tourism in small peripheral towns: the case of Jewish Heritage in Belmonte, Portugal. Tourism Planning \& Development, v. 13, n. 3, p. 310-32, 2015.

EUROPEAN COMMISSION. Closing the loop - an EU action plan for the Circular Economy. 2015. Disponível em: https://eur-lex.europa.eu/legal-content/EN/TXT/? uri=CELEX:52015DC0614. Acesso em: 4 dez. 2017.

FONSECA, J. J. S. Metodologia da pesquisa científica. Fortaleza: UEC, 2002.

GIL, A. Carlos. Como elaborar projetos de pesquisa. 4. ed. São Paulo: Atlas, 2007.

HOFFMANN, W. H.; SCHLOSSER, R. Success factors of strategic alliances in small and medium-sized enterprises an empirical survey. Long Range Planning, v. 34, n. 3, p. 357-81, 2001.

HU, T.-S.; LING, C. Y.; CHANG, S.-L. Technology-based regional development strategies and the emergence of technological communities: a case study of HSIP, Taiwan. Technovation, v. 25, n. 4, p. 367-80, abr. 2005.

KACHBA, Y. R.; HATAKEYAMA, K. Estratégias de inovação em APLs: viés para o desenvolvimento de produtos de moda. Produção, São Paulo, v. 23, n. 4, p. 751-61, out./dez. 2013.

LEITÃO, A. Economia circular: uma nova filosofia de gestão para o século XXI. Portuguese Journal of Finance, Management and Accounting, Aveiro, Portugal, v. 1, n. 2, p. 149-71, 2015.

MALAGUTI, C. Requisitos ambientais para o desenvolvimento de produtos: manual técnico. São Paulo: CSPD- Centro São Paulo Design, 2005.

MARINI, M. J.; SILVA, C. L. Desenvolvimento Regional e Arranjos Produtivos Locais: uma abordagem sob a ótica interdisciplinar. Revista Brasileira de Gestão e Desenvolvimento Regional, Taubaté, SP, v. 8, n. 2, p. 107-29, maio/ago. 2012.

MENDONÇA, F. M. Formação, desenvolvimento e estruturação de arranjos produtivos locais da indústria tradicional do Estado de Minas Gerais. Rio de Janeiro: UFRJ/COPPE, 2008. 324p. 
NASCIMENTO, A. C. D.; VALDEZ-PIZARRO, J.; MORAES, R. R. Estratégias para o fortalecimento ambiental das micro e pequenas empresas moveleiras de Marabá. Amazônia em Foco, Edição Especial: Empreendedorismo e Sustentabilidade, v. 1, p. 23-39, 2013.

OLIVEIRA, F. R.; FRANÇA, S. L. B.; SOUZA R. G.; RANGEL, L. A. D. Requisitos ambientais incorporados ao desenvolvimento de produtos em clusters e ecoparques industriais. Espacios, Caracas, Venezuela, v. 37, n. 11, p. 9, 2016.

OLIVEIRA, F. R., FRANÇA, S. L. B., RANGEL, L. A. D. Challenges and Opportunities for Circular Economy in a Furniture Local Productive Arrangement in Brazil. Resources, Conservation and Recycling, v.135, p. 202-209, 2018.

ROZENFELD, H.; FORCELLINI, F. A.; AMARAL, D. C.; TOLEDO, J. C.; SILVA, S. L.; ALLIPRANDINI, D. H.; SCALICE, R.; K. Gestão de desenvolvimento de produto: uma referência para a melhoria do processo. São Paulo: Saraiva, 2006.

RUIZ-SILVERA, C.; REYES, A.; MARTínEZ, R. Logros e impactos en el entorno social de un proyecto de cadena productiva local en bambú. Espacios, Caracas, Venezuela, v. 31, n. 2, p. 22-6, 2010.

SACHS, I. Rumo à ecossocioeconomia: teoria e prática do desenvolvimento. Paulo Freire Vieira (Org.). São Paulo: Cortez, 2007.

SALGADO, E. G.; SALOMON, V. A. P.; MELLO, C. H. P.; FASS, F. D. M.; XAVIER, A. F. Modelos de referência para desenvolvimento de produtos: classificação, análise e sugestões para pesquisas futuras. Revista Produção Online, Florianópolis, v. 10, n. 4, p. 886-911, dez. 2010.

SILVA, M. V. Apontamentos teórico-metodológicos para o conceito geográfico "Circuito Espacial da Produção": estudo de casos em Goiás- Mitsubishi em Catalão e Complem em Morrinhos. Boletim Goiano de Geografia, Goiânia, v. 34, n. 1, p. 73-91, jan./abr. 2014.

SINGER, P. Introdução à economia solidária. São Paulo: Fundação Perseu Abramo, 2002.

UNITED NATIONS FRAMEWORK CONVENTION ON CLIMATE CHANGE (UNFCCC). Report of the Conference of the Parties on its 21st session, held in Paris from November 30 to December 11. Ginebra: United Nations, 2015.

\section{Sobre os autores:}

Fábio Ribeiro de Oliveira: Doutor em Sistemas de Gestão Sustentáveis (UFF). Mestre em Sustentabilidade Socioeconômica Ambiental (UFOP). Especialista em Engenharia de Segurança do Trabalho (Faculdade Pitágoras). Graduado em Engenharia Ambiental (UFOP). Professor em cursos técnicos em meio ambiente e química do SENAI/CETIQT. Professor no curso técnico de segurança do trabalho, tecnólogo em gestão de recursos humanos e na pós-graduação em engenharia de segurança do trabalho (IF Sudeste/MG). Professor adjunto do Departamento de Engenharia Ambiental da UFBA. E-mail: fabio.ribeiro.de.oliveira@gmail.com, Orcid: http://orcid.org/0000-0002-2783-0157

Sergio Luiz Braga França: Doutor em Engenharia Civil (UFF), ênfase em Gestão, Produção, Qualidade e Desenvolvimento Sustentável. Especialista em Engenharia de Segurança do Trabalho (UFF). Graduado em Engenharia Civil (UFF). Professor associado I do Departamento de Engenharia Civil (UFF). Coordenador do Núcleo de Inovação e Tecnologia para a Sustentabilidade (NITS/UFF). Professor credenciado no 
Programa de Pós-Graduação em Sistemas de Gestão (LATEC/UFF). E-mail: sfranca@latec.uff.br, Orcid: http://orcid.org/0000-0003-1783-3167

Luís Alberto Duncan Rangel: Pós-Doutorado na Universidade de Zaragoza na Espanha. Doutor em Engenharia de Produção (UFRJ). Mestre em Engenharia de Produção (UFF). Graduado em Engenharia Mecânica (UCP). Professor da UFF. Professor Associado do Departamento de Engenharia de Produção da Unidade de Volta Redonda. Responsável pelo Grupo de Pesquisa do CNPq, "Teoria, Aplicação e Ensino de Pesquisa Operacional". Professor credenciado no Programa de Pós-Graduação em Sistemas de Gestão (LATEC/UFF). E-mail: duncan@metal.eeimvr.uff.br, Orcid: http://orcid.org/0000-0003-1431-9859 
